\title{
Reframing the Lecture versus Active Learning Debate: Suggestions for a New Way Forward
}

\author{
Todd Zakrajsek \\ Department of Family Medicine, School of Medicine, University of North Carolina at Chapel Hill, Chapel Hill, North Carolina, USA
}

\section{Abstract}

For nearly 1000 years, lecture has been the most frequently used teaching strategy in higher education. Over the past 20 years, there has been increasing pressure to stop lecturing and instead use more active and engaged teaching strategies. An unfortunate result of the attack on the lecture is that faculty members have resisted being told to completely abandon lecturing. This has critically slowed the adoption of more contemporary evidence-based teaching strategies that would likely have advanced student learning beyond where it is today. This article includes four key challenges regarding the "active learning versus lecture" debate. Issues presented address a better understanding of what is meant by "the lecture," a better understanding of the empirical studies comparing active learning to lecturing, a challenge to the claim that students do not learn well from the lecture, and that the comparison of active learning to lecturing is not an appropriate comparison. The primary position of this paper is that the adoption of contemporary evidence-based strategies designed to advance student learning is much more likely to be accepted and adopted by faculty members if the "active learning versus lecture" position is reframed in favor of an integrated position of combining lecture strategies with more active and engaged learning strategies. This approach would also be more consistent with existing evidence on teaching for deep learning.

Keywords: Active learning, learning, lecture, medical education, teaching

For nearly 1000 years, lecture has been an integral teaching method in higher education, dating back to the beginning of universities in Western Europe. ${ }^{[1]}$ There is currently a strong movement against the lecture, with published reports noting that the lecture is not effective, ${ }^{[2]}$ that one cannot learn from the lecture, ${ }^{[3]}$ and that lecturing may be unethical. ${ }^{\left[{ }^{[4]}\right.}$ Although criticism of the lecture is widespread, I think the argument that the lecture, or didactic, should be abolished is grossly inappropriate. I further argue that the result of this mistaken attack on the lecture has critically slowed the adoption of more contemporary evidence-based strategies that would greatly advance student learning.

The attack on the lecture began in the 1990s when a movement took hold in higher education to move from an emphasis on teaching to an emphasis on learning. ${ }^{[5-7]}$ The argument, well supported by current empirical evidence, is that educational strategies should move from a more passive situation of students continually receiving information to more active and engaged learning environments where students actively participate in the learning process. ${ }^{[2,8,9]}$ Freeman et al. ${ }^{[2]}$ went so far as to note that if the active learning versus lecture results

\begin{tabular}{|l|l|}
\hline \multicolumn{2}{|c|}{ Access this article online } \\
\hline Quick Response Code: & Website: \\
\hline & www.ehpjournal.com \\
\hline & \\
\hline
\end{tabular}

to date were instead an investigation of a health intervention, the studies would be "stopped for effect." Unfortunately, the move from lecturing to active learning has been slow. The slow progression is likely due to several fatal flaws in the literature on this topic. Here, I describe four important issues regarding the entire "active learning versus lecture" debate. I argue that instead of calling for the abolition of the lecture methods, ${ }^{[10]}$ we should instead be calling for the inclusion of more active and engaged learning strategies within the lecture format.

The first challenge in the standard "active learning versus lecture debate" is that it is not clear what is meant by the lecture method. If there is a call to eliminate the lecture, how should we eradicate something when we have not settled on what that thing is? Throughout higher education and medical education research, there is a common lack of operationalizing

Address for correspondence: Dr. Todd Zakrajsek, School of Medicine, University of North Carolina at Chapel Hill, Chapel Hill, North Carolina, USA.

E-mail: todd_zakrajsek@med.unc.edu

This is an open access journal, and articles are distributed under the terms of the Creative Commons Attribution-NonCommercial-ShareAlike 4.0 License, which allows others to remix, tweak, and build upon the work non-commercially, as long as appropriate credit is given and the new creations are licensed under the identical terms.

For reprints contact: reprints@medknow.com

How to cite this article: Zakrajsek T. Reframing the lecture versus active learning debate: Suggestions for a new way forward. Educ Health Prof 2018;1:1-3. 
the primary variable involved - the lecture. When published literature notes the "lecture" or "didactic," the terms are rarely defined. It seems individuals using the term expect that everyone explicitly understands the concept. However, there can be defined at least 12 different types of lectures. ${ }^{[11]}$ One type of lectures is the continuous exposition of information, also called the formal lecture. This type of lecture involves an instructor standing before a group of learners and presenting information nonstop and is often implicitly considered synonymous with the overall term of "lecture" or "didactic." However, this is only one form of lecture, and it is very different discussion lectures, Socratic lectures, demonstration lectures, storytelling lectures, and several other types of lectures. The lack of clear definitions is critical in the "lecture versus active learning debate." If we are going to criticize the lecture as being ineffective, we should certainly have a clear operationalized definition what is specifically meant by the lecture. There are times researchers do give solid definitions of the lecture. In the Freeman et al.' ${ }^{[2]}$ meta-analysis of engaged learning, "lecture" was defined as “...continuous exposition by the teacher." However, although their definition of lecture is clearly stated, those who cite this extensive and well-designed meta-analysis often fail to note the definition of a continuous expository and instead generalize the results to impinge all types of lectures.

Lectures also typically bring to mind monotone deliveries, boring presentation slides, and yellowed notes of old information. There are obviously many examples of poorly executed continuous exposition lectures, and in those cases, learning is certainly impacted. Providing examples of poor lectures does not mean that all lectures are bad. There do exist wonderfully delivered storytelling lectures, mesmerizing demonstration lectures, and thought-provoking Socratic lectures. We must be careful to not let the worse attributes of a teaching strategy define that strategy. Nothing should be defined simply based on the worse aspects of that concept.

As noted previously, there are many types of lectures. There are also many very different ways to engage students. ${ }^{[11]}$ Studies done on the effectiveness of the lecture versus active learning rarely define specifically the active learning pedagogy employed. For example, it is helpful to note research comparing problem-based learning to continuous exposition lectures, buzz groups to discussion lectures, and service-learning to storytelling lectures with variables that are better defined it would be possible to identify which instructional strategies were more effective than others.

The second issue with the claim that "engaged learning is more effective than lecturing" is that there are no empirical studies that directly compare engaged strategies to lecture as a continuous exposition of information. Studies investigating "lecture versus active learning" are nearly always "continuous exposition of information (traditional lecture) versus some form lecture with participation of students included." For example, Hake ${ }^{[9]}$ investigated lecture versus active learning by comparing the traditional classroom to the interactive classroom. However, although traditional classroom included only continuous expository of information, the interactive classroom was actually a combination of lecture and active learning. If a 50-min classroom session included a faculty member doing an expository lecture for $10 \mathrm{~min}$, followed by a 15 -min problem-based learning exercise with reporting out, and then concluded with a 25-min expository lecture, the classroom was placed into the interactive classroom condition. What is often lost is that the example is a 50-min class with $15 \mathrm{~min}$ of problem-based learning and $35 \mathrm{~min}$ lecture (10 min plus $25 \mathrm{~min}$ ). So, we should say $70 \%$ expository lecture with $30 \%$ problem-based activities. This is not a "lecture" versus "engaged learning" comparison, but rather a "continuous lecture" versus a combination of "lecture/engaged learning." In any study of health, if we had a weight reduction medication (Drug) and wanted to compare it to a behavioral intervention of exercise (Exercise), we would all be quick to see the flaw of a study that compared the Drug group to the Drug with Exercise group. It would be particularly problematic if the Drug with Exercise showed significant gains led to claims that "Exercise is more effective than the Drug treatment."

Virtually, every study comparing active learning to lecturing has some forms of lecturing in the active learning condition. In the meta-analysis by Freeman et al., ${ }^{[2]}$ studies in the "active learning" classification devoted as little as $10 \%$ of class time to engaged learning strategies, meaning the students were being lectured to $90 \%$ of the time. It is misleading to suggest lecturing is ineffective when comparing learning that involves $100 \%$ lecture (classified as lecture) to learning with $90 \%$ lecture (classified as active learning). This does, however, allow for a discussion based on "all lecture" versus "lecture with active learning."

The third issue is that the claim that one cannot learn from lecture is simply incorrect. Direct instruction has been researched heavily in psychology and shown for decades to be both effective and efficient. ${ }^{[12]}$ We all know the value of observing others and being given direct instruction. If you explain to a resident the importance of taking a proper history, along with a few pointers as to what to ask and how to respond to the patient, the resident will undoubtedly learn something about taking a proper history and physical. We all learn a great deal from reading research, which I am hopeful is happening in this article is of value in persuading you to as you read this article and reconsider the lecture versus active learning debate. Written work is no different from a lecture put to paper. Storytelling, a type of lecture, has been shown to be effective for centuries. How can it be said that reading, movies, and stories as passive and one-way as they are, cannot result in learning?

Knowing that lectures and direct instruction can result in learning will certainly result in resistance when a faculty member is told we must abandon the lecture because "one cannot learn from that type of teaching." Even when published studies demonstrate better learning from integration of some forms of lecturing with 
some forms of engaged learning strategies, this does not mean students those in the continuous exposition classes did not learn at all. For example, Freeman et al..$^{[2]}$ reported a $6 \%$ improvement in scores for students in courses with active learning as compared to all lecture. That is a substantial gain, but the findings do not indicate one cannot learn from direct instruction.

The fourth and final issue is that "active learning" versus "lecturing" is not appropriate by structure. The argument here seems to have emerged from the work of Barr and Tagg ${ }^{[7]}$ and others in the 1990s as noted previously in this paper that we should move from teaching to learning. Traditional lecturing in the form of a continuous exposition of information is often referred to as "lecture" or "didactic" and is often synonymous with teaching. Learning, or the acquisition of information, is typically thought of as having the students actively involved in the learning in some overt way. When students work in small groups to discuss a problem or some concept, it is described in terms of learning. When the instructor tells students the solution to a problem or explains some concept, it is described as teaching. Teaching is delivering information and learning is receiving information in a way that it can be used at a later time. It is inappropriate to say one is better than the other. Essentially, the movement of "active learning is more effective than lecturing," is really stating that "learning is more effective than teaching." In the cognitive psychology literature, there is a fundamental problem with the formation of this line of thought. It may be seen as a subtle distinction and based on the specific use of words, but specificity is how we advance science.

Leaders in higher education have been trying to move faculty from lecturing to active learning for over 20 years. The issues noted in this paper were developed to suggest why the move away from the lecture has not progressed more quickly. Yes, academe often moves slower than many would like, but 20 years is enough time that if the "abandon the lecture and do active learning message" had merit, lecturing would now be seen as an antiquated instructional strategy. The lecture has not gone away because faculty members resist giving it up, and evidence supports that it should not be given up entirely. The four issues noted in this piece helps explain the resistance. Clarifying the types of lectures and types of engaged learning would be a good place to start. All that said, to me, the challenge stems from the argument dating back to the 1990s that we should all stop lecturing (expository lecturing) and instead do active learning. When an individual is told, "to stop doing what you are doing and to do something else instead," it brings with it a defensive action and one must demonstrate the something moved toward is better than what is being done.
The literature, at present, does not present a clear case that engaged learning is better than lecturing. The literature is consistent that engaged learning strategies combined with expository lectures result in more learning than continuous expository lecturing. It is for that reason I call for a new direction in moving higher and medical education. Instead of a call to replace the lecture with active learning, I believe we should use a more evidence-based approach and augment well-designed specific types of lectures with various and appropriate active learning strategies. The point here is that instead of replacement, we need an adaptation and inclusion.

\section{Financial support and sponsorship}

Nil.

\section{Conflicts of interest}

Dr. Zakrajsek serves as an Executive Editor for Education in the Health Professions. Thus, peer-review of this article was performed independently by other members of the editorial team.

\section{RefEREnCES}

1. Brockliss L. Curricula. A history of the university in Europe. Vol. 2. Cambridge, England: Cambridge University Press; 1996. p. 565-620

2. Freeman S, Eddy SL, McDonough M, Smith MK, Okoroafor N, Jordt H, et al. Active learning boosts performance in STEM courses. Proc Natl Acad Sci 2014;111:8410-5.

3. Bajak A. Lectures Are not Just Boring they're Ineffective, too, Study Finds. Science;2014).Availablefrom:http://www.sciencemag.org/news/2014/05/ lectures- arent-just-boring-theyre-ineffective-too-study-finds. [Last accessed on 2018 Jul 14].

4. Handelsman MM. Is Lecturing Always Unethical: Should, and Can, Professors Keep their Mouths Closed? Psychology Today; 2011. Available from: https://www.psychologytoday.com/us/blog/ the-ethical-professor/201109/is-lecturing-always-unethical. [Last accessed on 2018 Jul 14].

5. King A. From sage on the stage to guide on the side. Coll Teach 1993;41:30-5.

6. Bonwell C, Eison J. Active Learning: Creating Excitement in the Classroom. Information Analysis-ERIC Clearinghouse Products; 1991. Available from: http://files.eric.ed.gov/fulltext/ED336049.pdf/. [Last accessed on 2018 Jul 14].

7. Barr RB, Tagg J. From Teaching to learning-a new paradigm for undergraduate education. Change 1995;27:6,12-26.

8. Deslauriers L, Schelew E, Weiman C. Improved learning in a large-enrollment physics class. Science 2011;332:862-4.

9. Hake R. Interactive-engagement vs. traditional methods: A six-thousand-student survey of mechanics test data for introductory physics courses. Am J Physics 1998;66:64-74.

10. Cornish A. Vermont Medical School Says Goodbye to Lectures. VPR News; 2017. Available from: http://wwwdigital.vpr.net/post/ vermont-medical-school-says-goodbye-lectures\#stream. [Last accessed on 2018 Jul 14].

11. Major CH, Harris M, Zakrajsek T. Teaching for Learning: 101 Intentionally Designed Educational Activities to put your Students on the Path to Success. New York, NY: Routledge; 2016.

12. Bandura A. Social learning theory of aggression. J Comm 1978;28:12-29. 